\title{
A Comparative Study on the Difference of "Face" in Western and Chinese Cultures
}

\author{
Man Zhang ${ }^{1}$, Xiaoxiao Chen ${ }^{1,2(\mathbb{\Delta})}$ \\ ${ }^{1}$ Guangdong Univeristy of Foreign Studies, School of English for International Business, \\ Guangzhou, China \\ ${ }^{2}$ Guangdong Univeristy of Foreign Studies, National Experimental Teaching Center of \\ Simultaneous Interpreting, Guangzhou, China \\ 983937087@qq.com, gracekot@qq.com
}

Keywords: Intercultural communication, Cultural difference, Face, Speech act.

\begin{abstract}
Intercultural communication is a communication activity among people in different cultures and different language backgrounds. Pragmatics investigates how language expressions are applied in concrete communication situations. Therefore, intercultural communication problems can be studied by adopting pragmatic theories. This research studies the cross-cultural difference of "face" through speech acts. With a purpose to reveal the differentiations of the concept of face ingrained in these two distinct cultures, this research is of importance in clearing conflicts and misunderstandings, and is also important to eliminate obstacles in real time interactions.
\end{abstract}

\section{Introduction}

Starting from the implementation of the open policy in 1978, China gradually began to establish diplomatic relationships with other western countries. Up to December 2001, China was formally approved to be a member of WTO, and international activities ranging from economy, politics, trading, to health welfare are rapidly carried daily. Intercultural communication happens in almost every corner of our modern community. Moreover, it is well known that language is a composite part of culture and serves as the carrier of language. And the wide spread of language interaction reflects influence from culture. Therefore, studying the cause why people have diversified concepts toward "face" behind the different cultural backgrounds could help us avoid making mistakes in intercultural communications.

\section{Literature review}

"Face" was a concept firstly introduced to America by Chinese anthropologist Hu [1]. Goffman [2], a Canadian-American sociologist, conducted his study on "face" based on Hu's theoretic foundation, and he considered that face is a personal positive social value built by our individual selves in communications when we behave properly. Brown and Levinson [3] also made their systematic research on "face" and put forward "Face Saving Theory" in their book "Universals in Language Usage: Politeness Phenomenon”. This theory, on the basis of Goffman's concepts, includes three elements: face, face threatening acts and politeness strategies. Until 1987, Brown and Levinson [4] continued to further their investigation of "Face Saving Theory" and "Politeness" strategies. They believed "face" is a public image that each social member strives to build and erect. Later, Scollon and Scollon [5] carried forward their research on "face" further and indicated that "face" is paradoxical.

This research mainly conducts a comparison and contrast of "face" concepts from the 
perspective of western and Chinese cultures. Because western cultures think highly of individualism, while Chinese culture values collectivism instead, differentiations of cognition exist between these two cultures.

\section{Knowledge about "Face"}

"Face" is a public image that each social member strives to build and erect. It is a social psychological construction rooted in culture and formed and manifested in interpersonal communication. "Face" contains two sides: positive face and negative face. The former expresses wishes to be admired, respected and welcomed, whereas the latter shows human being's inclination not to be forced, compelled, demanded or interfered by others. In Brown and Levinson's opinion, conversationalists both confront the possibilities of face-threatening positive or negative from the opposite side. Therefore, in their minds, the overwhelming majority of speech acts are dangerous for "face", which is the so called "face threatening acts". In this premise, politeness becomes a commonly used strategy to mitigate the intensity of threats. Politeness principle is established in the field of pragmatics for avoiding or smoothening the unpleasant feelings or awkward situations during the course of communication activities. Both parties should display their decent images and cooperate with each other to achieve their communication purpose cheerfully. However, there are differences in the concept of "face" between Chinese and western cultures, which lead to the different choice of politeness strategies. In social communications, we are not only supposed to respect others' positive face, but also should take good care of their negative face. In the long run, our respect for others could be helpful for earning "face" for ourselves. Because "face" is the most basic psychological demand for all social men, everyone could protect and defend his "face” from threats by taking necessary protective measures. The safest way to protect our own "face" is not to hurt others" "face". Remember the common courtesy and act toward others as you want them to act toward you. This is the golden rule worldwide, but an interesting phenomenon still exists in reality. That is people from different cultural backgrounds act rather differently to guard their individual face. One of the major reasons is that different countries have different cognition of "face", and different cognitive conceptions guide different behaviors.

\section{Historical background of "Face" concept formation in Western and Chinese cultures}

Western cultures originated from ancient Greek culture, a world civilization from 20 century BC. At the very beginning of the development of the newly born civilization, freedom and democracy were highly advocated. Individual rights, interests and values are given unprecedented emphasis, so that individualism comes into being in the long history of the development of westerns civilization, pertaining to societies in which the ties between individuals are loose. Individualists promote the exercise of one's goals and desires and value independence and self-reliance as well as self-realization. Besides, individual decisions are valued over group decisions, and each individual has a greater right to thought and opinions which differ from those held by the majority. They care more about the equality and fairness of opportunities and rights, but give little attention to the hierarchical differentiations and social power distances. In short, individualism is a concern for yourself as an individual as opposed to concern for the priorities and rules of the group to which you belong.

By contrast, Chinese culture stems from Confucian culture, formed as early as two thousand years before. In this set of cultural system, harmony between man and nature is the core idea. And 
kindheartedness is the excellent merit and requisite property of humans. Man is an integral part of the nature. In collectivist society, there is the belief that the group comes first. Such culture would contain well-defined social networks in which people are expected to put the good of the group ahead of their own personal freedom, interests or success. Group members try to fit into their group harmoniously with a minimum of conflict or tension. Everyone has his own specific obligation to assume his responsibility according to his social role. Group interests prevail over individual interests, and the individual derives his social identity from the group of which he or she is a member. Chinese traditional culture appreciates social integration and stresses individual should be subordinated to group. In addition, there are sets of established moral rules and ideal personality standards to regulate our behaviors, such as respecting the aged and taking care of children. We could build a good public image when we conduct in accordance with those rules.

The above brief analysis has explained the underlying reasons of conceptual differentiations of "face". Therefore, in authentic intercultural communications, conversationalists must keep this information in their minds, and adapt themselves to the changing communication rhythm.

\section{Concrete embodiment of "Face" differences in speech acts}

\section{1 "Face" difference in address}

The greeting ways are completely different between Chinese and western cultures.

In western countries, there are two categories of the use of address language: reciprocal address form and nonreciprocal address form. The choice of which form comes into use is determined by specific social factors like power and equality. When conversationalists have equal social status, they tend to use the same category of address that is reciprocal address form featured by adding a title to other's last name. When the situation is reversed, namely there is a certain social status gap between two parties, the senior side would call the junior's name directly, which is meaningful for showing their amiableness and giving enough face to the junior, while the junior would be solemn to call them "sir" or "madam" to display their respects and save the positive face of the senior.

Things are quite different in China. In our traditional cultures and virtues, "reduce ourselves to the dust and lift someone else to the air” is regarded as a criterion to judge whether a person knows how to behave politely. Influenced by social structure, blood relationship, clan affinity etc., the use of address language shows a power disposition. People like to add some affixes to others' first name or last name for the purpose of taking care of other's positive face and maintaining harmonious interpersonal relationships. In addition, another interesting phenomenon is also unique to Chinese. People are used to greet non-relatives and even strangers in a way similar as greeting their blood relatives. Anyone who is about the same age will be called "sister" or "brother" and those who are old will be named "grandpa" or "grandma" especially when we need help. Many westerners can't figure out why Chinese are so intimate and amicable, even though they get to know each other just a few minutes ago. On the other hand, it embodies the collectivism ideology in Chinese culture.

\section{2 "Face” difference in apology}

The difference in apology reflects the difference in the concept of "face".

Firstly, in terms of the frequency, westerners apologize far more than Chinese people. The moment they make some annoying movements or make some loud noise, they will instantaneously make apology to ask for forgiveness. In China, we could admit our mistakes only when our words or behaviors cause actual hurts or damages to others.

In the second place, the conversation context also directly influences the differences in the 
behavior of apologies. Hall [6] proposed the concepts of high-context culture and low-context culture. The former stressed collectivism, in which people speak in an indirect manner, being respectful, and maintaining harmony. They consider it rude to be too direct in speech. The latter emphasizes individualism, in which people speak directly and says what they mean without adding unnecessary details or formulae. They are suspicious of people who speak indirectly.

Chinese culture is a typical high-context culture. People advocate harmony and try their best to avoid conflicts and contradictions in public. Once the conflict happens, direct and immediate apologies will be made to save face in case of contradiction intensification. To the contrary, western culture is the representative of low-context culture. Everyone could retain his own opinion and stick to distinct value. They feel repulsive towards threatening face acts. Quarrels frequently occur because both sides urge to defend their individual face.

\section{3 "Face" difference in request}

In western cultures, when people request others to do something, they usually start with "please" or "could you please" to show politeness and respect, because everyone dislikes being forced or compelled to do something even though it is within their capacity. Individualists value absolute equality between people. In their minds, there is no obligation or responsibility to provide you with assistance. If you demand directly, they will consider you have threatened their face. Consequently, you do not get what you want, but also offend others.

In China, people are inclined to send out a precious gift, treat you a big meal, or even provide some small benefits to you before they express their true intentions. It is our shared feeling that direct and abrupt request without any signs make us uneasy. As each of us has our own business to deal with, we are constantly fretting over family, work and life. In this case, we should give more consideration for each other. A good attitude and pleasant words are indispensable, partly to indicate our sincerity, partly to show our respect for others.

Moreover, we Chinese always put ourselves at a lower status when we wish others to do some things for us. For instance, "I beg you to help me". This behavior is seemly unacceptable in westerners' minds, which not only hurts the personal's own face, but also forces the opposite side into an embarrassing situation where he has no choice but to accept the request.

\section{4 "Face" difference in refuse}

The way Chinese people reject others in most cases is indirect and euphemistic, while the westerns are straightforward and explicit.

For our Chinese, we often emphasize the sense of collective cooperation. Under the Influence of traditional culture, the expression of Chinese language is becoming ever more sophisticated. The most direct manifestation is that every word the Chinese say has a deeper connotation. Moreover, we tend to take care of the surroundings and people presented while talking, and we care deeply about how others feel. So in rejecting others, the Chinese expression is more subtle and implicit, especially when faced with higher-ups or higher-status people. As to the English-speaking countries, their nationals are individualistic and independent, and they prefer to communicate their differences openly and carry themselves in an independent manner. As a result, people refuse others in a more straightforward approach, unless it is necessary.

If a westerner is invited to a dinner, but he happens to have some urgent issues to deal with, he would firstly show his gratitude for this kind invitation, and then he will explicitly decline this invitation by giving his reasonable reasons. Because he has expressed appreciation ahead of the rejection, so he shrinks the threatening force, which could hurt other's "face", to a minimum level. Situation will turn out to be different if it happens on Chinese people. All of us know it is impolite 
or rude to turn down others directly face to face. So facing with an invitation to dinner that we do not want to go, we Chinese people would choose to tell white lies or make up some excuses to decline. We often hear "How unluckily that I have had an appointment today. Maybe next time when you are available, we could get together to have a meal." Most of us understand it is a sheer excuse to refuse the invitation in a roundabout way.

\section{5 "Face" difference in etiquette}

In cross-cultural communication, there are many differences in the presentation of etiquettes. Its root can be traced to cultural differences. The following part will give detailed description of such difference from two aspects: table manners and compliment response.

Table manners are the rules of etiquette used while eating, which may also include the appropriate use of utensils. Different cultures observe different rules for table manners. In China, there exist a special way to show hospitality. The host will constantly say "We feel very sorry that we don't prepare enough dishes” even though the table has been piled with plates. Apart from this, the host sometimes will help guests to choose foods with their chopsticks, saying "eat more". An absurd moment is when the guest eats little food the host will be very regretful and remorseful. They blame themselves for not having a good cooking technique, which will make guests feel ill at ease.

By contrast, westerners behave more casually. Less or more dishes they have provided, they only say "help yourself”. Guests could enjoy great freedom and would really feel at home.

Another aspect is response to compliment. Chinese people's reaction to compliment is distinct from westerners, which is caused by cultural differences. In English people's opinion, politeness is to praise and accept the compliment. In China, people believe in being “modest, respect, kind" and would like to praise others and devaluate ourselves, in order to maintain a harmony relationship with people. Facing heartfelt compliments, westerners are likely to response with "Thank you" with a smile. Their willingness to accept the compliment and their prompt feedback are conducive to maintaining "face" of two sides. However, in the same situation, Chinese people tend to disagree and denigrate. They would downplay the object of the compliment and openly express their embarrassment over the compliment. After disagreeing with the compliment giver, the Chinese people would offer some explanations to justify their self-denigration. So the different responses to compliment could cause misunderstanding in intercultural exchanges if we do not have this kind of cultural reserves.

\section{Conclusion}

The first rule of intercultural communication is that each participant should understand the value of another culture and the second rule is that each communicator should adapt his/her communication to the value of a different culture. Western culture pursues individualistic traits; Chinese culture stresses collective thoughts. Therefore, people under two extremely distinct cultural environments generate different cognitive conceptualizations, especially in "face". Pragmatic mistakes often occur due to the overlook of these differences. In order to behave properly in intercultural communication, both Chinese and westerners should have a good command of cultural background knowledge.

Being an important integral part of pragmatics, "face theory" and "politeness strategy" should be attached great importance, as they seem to have penetrated almost all intercultural exchanges. To analyze the existent differences and then find out the underlying factors could help us form a general comprehension of "face", which is of great benefits to remove communication obstacles 
and facilitate successful exchanges.

\section{Acknowledgments}

This work was partially supported by the Graduate Education Innovation Plan of Guangdong Province (2015JGXM-MS22) and the Science and Technology Project of Guangdong Province, China (2017A020220002).

\section{References}

[1] Hu H C. The concept of face in China. American Anthropologist, 46: 45-64, 1944.

[2] Goffman E. Interaction Ritual: Essay on Face-to-face Behavior. New York: Doubleday Anchor, 1967.

[3] Brown P. and Levinson S. Universals in language usage: Politeness phenomena. In E.N. Goody, editor, Question and Politeness: Strategies in Social Interaction, Cambridge: Cambridge University Press, 1978.

[4] Brown P. and Levinson S. Politeness: Some Universals in Language Usage. Cambridge: Cambridge University Press, 1987.

[5] Scollon R. and Scollon S W. Intercultural Communication. Oxford: Blackwell, 1995.

[6] Hall E T. Beyond Culture. New York: Anchor press, 1976. 